\title{
EFFECT OF METHEMOGLOBINEMIA ON THE VISUAL THRESH- OLD AT SEA LEVEL, AT HIGH ALTITUDES, AND AFTER EXERCISE
}

\author{
By OSCAR BODANSKY ${ }^{1}$ AND CHARLES D. HENDLEY \\ (From Biochemistry Section, Medical Division, Chemical Warfare Service, Edgezwood, Maryland, \\ and Laboratory of Biophysics, Columbia University, New York City)
}

(Received for publication April 6, 1946)

Experiments by one of us (1) have shown that methemoglobinemia exerts a protective effect in dogs against poisoning due to inhalation of $\mathrm{HCN}$ and $\mathrm{CNCl}$. The possibility of applying these findings in man raised the question as to the extent to which methemoglobinemia would impair various physiological functions. Several groups of investigators (2 to 4 ) have found that a rise in the threshold of the dark adapted eye occurs during anoxia induced by low oxygen tensions, and have considered this visual test a very sensitive criterion of this type of anoxia. Accordingly, it was decided to determine whether the anoxia due to methemoglobinemia would affect the visual threshold $(a)$ at sea level, $(b)$ at lowered oxygen tensions, and $(c)$ after exercise.

\section{EXPERIMENTAL}

Methemoglobinemia was induced by the ingestion of $\mathbf{p}$ aminopropiophenone. This substance was shown by Vandenbelt, Pfeiffer, Kaiser and Sibert (5) to be a potent methemoglobin-former in animals. Doses ranging from 1 to $2 \mathrm{mgm}$. per $\mathrm{kgm}$. were dissolved in a minimal volume of propylene glycol, usually not more than $7 \mathrm{ml}$., and administered by mouth. Propylene glycol, without dissolved p-aminopropiophenone, was also given to a few individuals.

The concentration of methemoglobin was determined by a slight modification of the method of Evelyn and Malloy (6) and expressed as per cent of the total blood pigment. After ingestion of the p-aminopropiophenone in propylene glycol, the concentration of methomoglobin usually rose to a maximal value in about an hour. The concentration then remained fairly constant for about another hour when it began to decrease slowly. Measurements of the threshold were usually made during the period of constancy of the methemoglobin concentration, i.e. 1 to 2 hours after the ingestion of the drug. In the earlier experiments, a sufficient number of blood samples was taken so as to obtain a curve of the change in methemoglobin concentration, and to assure accurate estimation of the methemoglobin concentration at the time of measuring the dark adaptation.

1 Lt. Colonel, M.C., A.U.S. Present address : Cornell University Medical College, New York City.
The thresholds were measured with a Hecht-Shlaer adaptometer, Model 3. This instrument has a $3^{\circ}$ blue test field which appears $7^{\circ}$ below a red fixation point. The test field is exposed in flashes of 0.2 second, accurately controlled by a pendulum shutter. The subject is seated comfortably at the instrument and views the test field binocularly with the natural pupil. The device for controlling the shutter and exposing the field is easily accesible to the subject. The experimenter is seated directly across from the subject, at the other side of the instrument, where he can regulate and note the brightness of the test field. At a signal from the experimenter, the subject operates the shutter and informs the experimenter whether or not he has been able to discern the exposed field. The general principles and technique of dark adaptation measurements have been discussed by Hecht and Shlaer in describing their Model 1 adaptometer (7).

The measurements of the thresholds were expressed as $\log$ micromicrolamberts. The absolute values of these measurements are not relevant to the present problem and are not recorded here. The changes in the thresholds are expressed in the present paper in logarithmic units. Changes of $0.1,0.2,0.3 \mathrm{log}$ units correspond, respectively, to changes of 26,59 and 100 per cent in the threshold.

To avoid exposure to sunlight en route to the laboratory, the subjects wore dark red goggles. The subjects were then kept in a dark room for at least 30 minutes before the visual threshold was determined. p-Aminopropiophenone was then administered as described above. A blood sample was taken at the end of about an hour; during this procedure, the subject's eyes were covered, or a dim red light was used, while the blood was being taken. The visual threshold was again determined until it was constant, and another blood sample taken.

In those experiments in which the effect of lowered oxygen tension was determined, the subject was dark adapted and the threshold determined until a constant value was obtained. A nose oxygen mask was then adjusted and the threshold determined in a flow of 20 per cent oxygen. A 13 per cent oxygen mixture was then switched in for 15 minutes and the threshold determined at the end of this time. In most instances, the subject was then allowed to breathe room air for about 3 minutes; this was followed by 15 minutes of 10 per cent oxygen unless the subject became distressed. Occasionally, the subject was transferred directly from a 13 per cent to a 10 per cent oxygen mixture. The visual threshold was determined at this time, and again after the subject had been returned to room air. 
This entire procedure was repeated after the induction of methemoglobinemia.

The effect of excerise on dark adaptation was determined in 4 trained and 8 untrained subjects, as follows: The subjects were dark adapted and the visual thresholds determined. They then mounted the cycle ergometer and performed usually 3 , and in some instances 5 , minutes of exercise at various loads. Records of these loads were kept, but no correlation was found between the magnitudes of these loads or the degree of training and the visual effects. The work done ranged from about 20,000 foot pounds for the untrained individuals, to about 30,000 to 35,000 foot pounds for the trained individuals. The thresholds were determined within 2 minutes after the end of the exercise bout, and in most instances, several times again within the next 10 to 20 minutes. Some of the individuals received this exercise test several times, each time on a different day. When the effect of methemoglobinemia was to be determined, p-aminopropiophenone was administered immediately after the first post-exercise threshold determination. To save time, and since it was known on the basis of previous experience that the concentration of methemoglobin was negligible during the first 5 to 10 minutes after administration of the drug, several threshold determinations were made during the period to ascertain the effect of the bout of exercise during the non-methemoglobinemic period. The subjects then donned red goggles and were allowed to leave the dark room for about 30 to 45 minutes. They returned to the dark room and remained there for about $15 \mathrm{~min}$ utes before threshold measurements were begun. A blood sample for determination of methemoglobin concentration was taken just before exercise, when, in accordance with previous experience, the concentration was maximal and constant. The threshold was determined within 2 minutes after exercise and again 1 or more times during the course of the next 15 to 20 minutes.

\section{RESULTS}

Effect of methemoglobinemia on visual threshold at sea level. Sixty-four determinations of the effect of methemoglobinemia on the visual threshold at sea level were made in 32 subjects at various times and in connection with the several experiments. These included 3 determinations in which propylene glycol without dissolved p-aminopropiophenone was administered, and 2 determinations in which, although $\mathrm{p}$-aminopropiophenone was apparently taken, no methemoglobinemia resulted. The changes in the threshold are shown in Figure 1.

Inspection of Figure 1 shows a preponderance of increases in threshold, but no apparent correlation of increase in threshold with degree of methemoglobinemia. Detailed analysis shows that the average or mean increase, excluding the 5 values

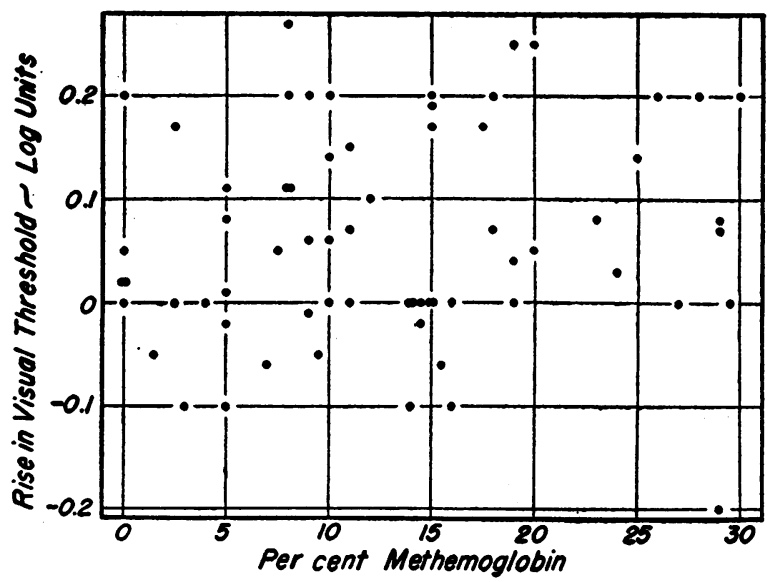

Fig. 1. Effect of Methemoglobinemia on the Visual Threshold of the Dark Adapted Eye

in subjects in whom no methemoglobin was formed, was $0.063 \log$ units $(t=4.5 ; P=<0.01)$. Apparently, this increase was significant. However, comparison of this change with those observed in 5 men receiving propylene glycol without p-aminopropiophenone and subjected to the same procedure of veni-puncture, etc., indicated that this increase was of the same order of magnitude and could not be ascribed to the methemoglobinemia per se. Moreover, correlation of the increase in the visual threshold with the degree of methemoglobinemia for all the 64 determinations gave a correlation coefficient, $r$, equal to 0.108 . The probability that this value might arise by chance is greater than 0.1 . It may be concluded, therefore, that there was no significant increase in the visual threshold at sea level in individuals having concentrations up to 30 per cent methemoglobin.

Effect of methemoglobinemia on visual thresholds at simulated high altitudes. The visual threshold was determined in a series of men breathing 13 per cent oxygen (12,000 feet) and 10 per cent oxygen (18,000 feet) before and after the induction of various degrees of methemoglobinemia (Table I). It may be seen that before the induction of methemoglobinemia, the average rise in the threshold was $0.13 \log$ units at 13 per cent oxygen, and $0.51 \log$ units at 10 per cent oxygen. Statistical evaluation gave respectively, $t$ values of $2.7(P=0.03)$ and $5.3(P=<0.01)$. These increases are significant and in good agreement with those previously reported by other workers 
TABLE I

Effect of methemoglobinemia on visual thresholds at simulated high altitudes

\begin{tabular}{|c|c|c|c|c|}
\hline \multirow{2}{*}{ Name } & \multicolumn{2}{|c|}{ Increase in threshold } & \multirow{2}{*}{$\begin{array}{l}\text { Increase in } \\
\text { threshold in } \\
\text { methemo- } \\
\text { globinemia }\end{array}$} & \multirow{2}{*}{$\begin{array}{l}\text { Concen. } \\
\text { of methe- } \\
\text { moglobin }\end{array}$} \\
\hline & $\begin{array}{l}\text { Without } \\
\text { methemo- } \\
\text { globinemia }\end{array}$ & $\begin{array}{c}\text { With } \\
\text { methemo- } \\
\text { globinemia }\end{array}$ & & \\
\hline & $\log$ units & $\log$ units & $\log$ units & per cent \\
\hline
\end{tabular}

a. At 13 per cent oxygen $(12,000 \mathrm{ft}$.)

\begin{tabular}{l|r|r|r|r}
\hline E.A. & 0.12 & 0.22 & 0.10 & 0 \\
J.B. & 0.20 & 0.35 & 0.15 & 1 \\
H.S. & 0.55 & 0.60 & 0.05 & 2 \\
W.W. & 0.12 & 0.25 & 0.13 & 2 \\
J.S. & 0.13 & 0.15 & 0.02 & 5 \\
J.T. & 0.10 & 0.10 & 0.00 & 8 \\
W.Mc. & -0.04 & 0.05 & 0.09 & 9 \\
R.K. & 0.19 & 0.11 & -0.08 & 15 \\
D.S. & 0.04 & 0.28 & 0.24 & 19 \\
D.S. & 0.04 & 0.50 & 0.46 & 20 \\
G.G. & 0.00 & -0.02 & -0.02 & 23 \\
E.S. & -0.02 & 0.05 & 0.07 & 24 \\
& & & & \\
Average & 0.13 & & 0.10 & \\
t value & 2.7 &. & 2.45 & \\
P value & 0.03 & & 0.04 & \\
\hline
\end{tabular}

b. At 10 percent oxygen $(18,000 \mathrm{ft}$.)

\begin{tabular}{l|r|r|r|r}
\hline J.B. & 0.85 & 0.85 & 0.00 & 1 \\
W.W. & 0.92 & 0.75 & -0.17 & 2 \\
H.S. & 0.35 & 0.30 & -0.05 & 3 \\
W.Mc. & 0.56 & 0.85 & 0.29 & 8 \\
J.T. & 0.47 & 0.68 & 0.21 & 10 \\
R.K. & 0.49 & 0.31 & -0.18 & 15 \\
E.S. & 1.45 & 0.70 & -0.75 & 15 \\
W. Mc. & 0.20 & 0.30 & 0.10 & 18 \\
W.T. & 0.50 & 0.70 & 0.20 & 18 \\
D.S. & 0.24 & 0.60 & 0.36 & 20 \\
D.S. & 0.24 & 0.48 & 0.24 & 20 \\
J.McF. & 0.30 & 0.51 & 0.21 & 21 \\
R.K. & 0.23 & 0.83 & 0.60 & 29 \\
D.S. & 0.22 & 0.60 & 0.38 & 30 \\
Average & 0.51 & & 0.10 & \\
t value & 5.3 & & 1.18 & \\
P value & $<0.01$ & & $>0.2$ & \\
\hline
\end{tabular}

for the effect of altitude on dark adaptation (2 to 4$)$.

Table I also shows the changes in the rod threshold resulting from the induction of various degrees of methemoglobinemia at 13 per cent and 10 per cent oxygen mixtures. At a 13 per cent oxygen mixture, the rises in the visual threshold after the induction of methemoglobinemia averaged $0.10 \mathrm{log}$ unit higher than prior to such induction. This difference was just significant $(t=2.45 ; P=0.04)$. At a 10 per cent oxygen mixture, the difference between the rises in the visual threshold before and after induction of methemoglobinemia was $0.10 \mathrm{log}$ unit $(t=1.18 ; P=>0.2)$. Exclusion of the $2 \mathrm{ex}-$ treme values, -0.75 for $\mathrm{E}$. S. and 0.60 for R. K., gave a rise of $0.13(t=2.37 ; P=0.04)$.

These increases in the visual thresholds as the result of induced methemoglobinemia appear to border on significance. However, it should be noted that here, as in the experiments at sea level, the induction of methemoglobinemia of whatever degree, was accomplished by the drinking of a solution, and accompanied by 1 or more venipunctures, procedures to which the non-methemoglobinemic individuals were not subjected. Correlation of the increase in the visual thresholds with the degree of methemoglobinemia gave coefficients of 0.163 with a $P$ value of $>0.1$ for the experiments at 13 per cent oxygen, and of 0.483 with a $P$ value of 0.07 for those with 10 per cent oxygen. In view of these considerations and the small number of cases, there is no evidence for concluding that methemoglobinemias ranging up to 30 per cent significantly alter the visual thresholds at simulated altitudes of 12,000 and 18,000 feet.

Effect of exercise on the visual threshold in nonmethemoglobinemic and methemoglobinemic individuals. Sixteen determinations were carried out on 8 non-methemoglobinemic individuals before and within 1 to 2 minutes after exercise, as previously described. Table II shows that there was

TABLE II

$\begin{array}{cc}\begin{array}{c}\text { Changes in visual threshold in non-methemoglobinemic } \\ \text { individuals immediately after short bout of exercise } \\ \text { Increase in } \\ \text { rod threshold }\end{array} \\ \text { Name } & \text { log units } \\ & 0.10 \\ \text { D.B. } & 0.20 \\ & 0.10 \\ & -0.30 \\ \text { H. } & 0.00 \\ \text { O. } & 0.05 \\ \text { B.S. } & 0.10 \\ & -0.10 \\ \text { C.H. } & 0.20 \\ \text { G. } & 0.20 \\ \text { T. } & 0.00 \\ \text { B. } & 0.10 \\ \text { Average } & 0.00 \\ & 0.00 \\ & 0.10 \\ & 0.15 \\ & 0.006\end{array}$

Duration of exercise 3 minutes in all but 4 experiments which were 5 minutes. Total amount of work ranged from 17,200 foot pounds to 37,200 foot pounds; lower amounts were done by untrained men, higher amounts by trained men. 
TABLE III

Comparison of changes in thresholds immediately after exercise* in individuals before and after the induction of methemoglobinemia

\begin{tabular}{l|c|c|c|c}
\hline \hline & \multicolumn{3}{|c|}{ Threshold change } & $\begin{array}{c}\text { Concen- } \\
\text { tration of } \\
\text { methemo- } \\
\text { globin }\end{array}$ \\
\cline { 2 - 3 } & $\begin{array}{c}\text { Prior to } \\
\text { methemo- } \\
\text { globinemia }\end{array}$ & $\begin{array}{c}\text { During } \\
\text { methemo- } \\
\text { globinemia }\end{array}$ & Difference & \\
\cline { 2 - 4 } Du B & log units & log units & log units & per cent \\
H. & -0.10 & -0.20 & -0.10 & 15 \\
H. & 0.00 & -0.30 & -0.30 & 8 \\
O. & -0.15 & -0.30 & -0.15 & 10 \\
O. & 0.20 & 0.00 & -0.20 & 19 \\
B.S. & -0.10 & -0.20 & -0.10 & 14 \\
C.H. & -0.15 & -0.10 & 0.05 & 11 \\
S. & 0.00 & -0.20 & -0.20 & 19 \\
K. & 0.10 & -0.05 & -0.15 & 11 \\
W. & -0.10 & -0.10 & 0.00 & 26 \\
McF & 0.10 & -0.20 & -0.30 & 15 \\
Average & -0.20 & -0.20 & 0.00 & 10 \\
t value & -0.036 & -0.17 & -0.13 & \\
P value & 1.0 & 5.9 & 4.1 & \\
\hline
\end{tabular}

* Duration of exercise: 3 minutes.

no appreciable alteration in the threshold as the result of exercise. The average change was 0.006 $\log$ unit, and not significant.

In 11 experiments on 9 individuals, the exercise test was done before the administration of paminopropiophenone, and again after administration when a maximal concentration of methemoglobin had developed. Table III shows that the changes in thresholds obtained within 2 minutes after the end of exercise, before induction of methemoglobinemia, were negligible; the average change was $-0.036 \log$ unit $(t=1.0 ; P=0.3)$. After methemoglobinemia had developed, 10 of the 11 tests showed a decrease in threshold as a result of exercise. The average decrease was 0.17 $\log$ unit, and was definitely significant $(t=5.9$; $P=<0.01)$. When the differences between the threshold changes before and after methemoglobinemia were calculated, it was found that these differences were also significant. The average change was $-0.13 \log$ unit $(t=4.1 ; P=<0.01)$.

It was also noted that about 5 to 10 minutes after the end of exercise, the threshold rose above the value immediately after exercise in both methemoglobinemic and non-methemoglobinemic individuals. Table IV shows these increases in 27 determinations on 12 individuals without methemoglobinemia, and in 11 determinations on 9 individ- uals with methemoglobinemia. It may be seen that the average increase was $0.14 \log$ unit $(t=4.2$ i $P=<0.01)$ in the former, and $0.32 \log$ unit $(t=5.0 ; P=<0.01)$ in the methemoglobinemic individuals. The latter represents a change from $-0.17 \mathrm{log}$ unit below the normal threshold to an increase of $0.15 \mathrm{log}$ unit above the normal threshold. In other words, 5 to 10 minutes after exercise, both the non-methemoglobinemic and methemoglobinemic individuals showed the same rise above the normal visual threshold.

\section{DISCUSSION}

McFarland, Roughton, Halperin and Niven (8) have recently reported that carboxyhemoglobinemia raises the brightness discrimination threshold in cone vision as measured by the Crozier and Holway visual discriminometer, and that this effect and the increase in threshold at low oxygen

TABLE IV

Comparison of thresholds 5 to 10 minutes after exercise with those immediately after exercise

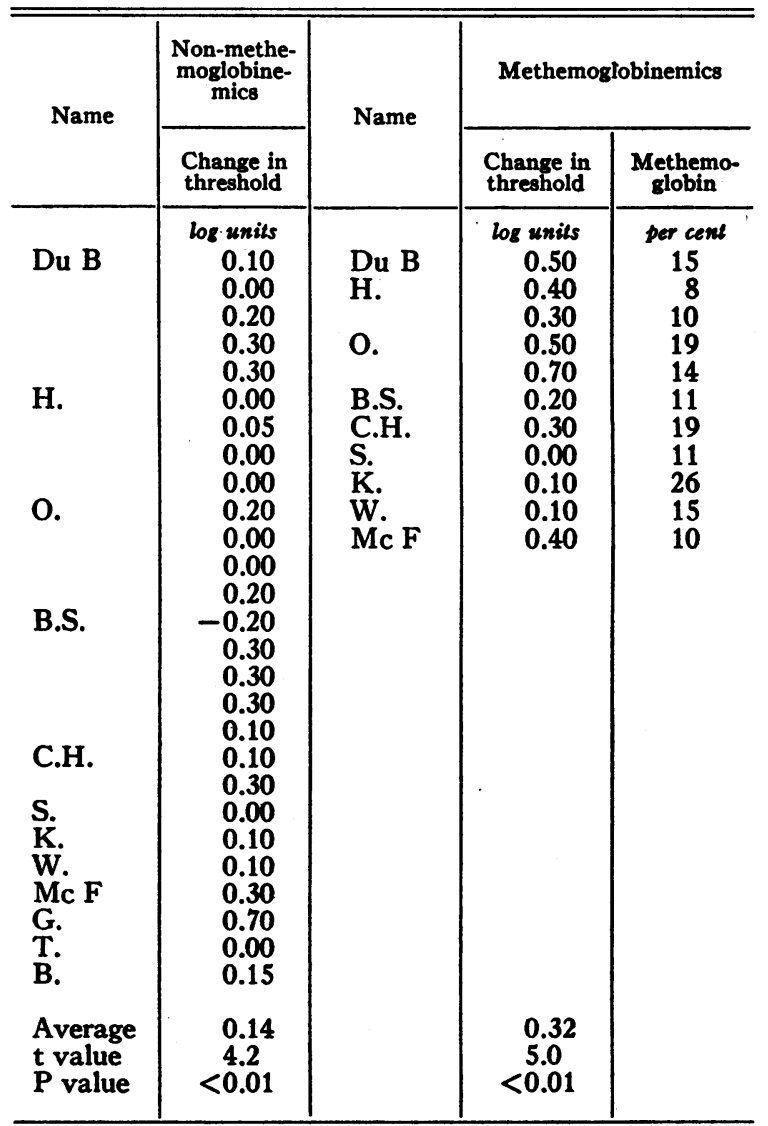


tensions (simulated high altitudes) are additive. In the present study, it has been found that methemoglobinemia does not alter the threshold in rod adaptation, either at sea level or at high altitudes.

The possibility exists that the anoxia of carboxyhemoglobinemia or methemoglobinemia raises the threshold of the cones but not that of the rods. There are, however, no existent data to lend support to this possibility. In anoxia due to low oxygen tensions, the shape of the dark adaptation curve is the same; the whole curve is shifted to a higher level, and both the cone and rod thresholds are raised to the same extent (9).

An attempt to explain the differences in effect on sensitivity to light in methemoglobinemia and carboxyhemoglobinemia may also be made by considering the comparative degrees of tissue hypoxia in these 2 conditions up to levels of about 30 per cent carboxyhemoglobinemia or methemoglobinemia. Adjustments in the oxygen unloading in the tissues up to this level of carboxyhemoglobinemia are accomplished not by changes in cardiac output, but by decreases in the venous oxygen tension $(10,11)$. Both methemoglobinemia and carboxyhemoglobinemia shift the oxygen dissociation curve of the residual oxyhemoglobin to the left, and render the curve less sigmoid and more hyperbolic. This shift is less marked in the case of methemoglobinemia $(12,13)$. Therefore, for a given amount of oxygen unloading, a lower venous and tissue oxygen tension is reached in the case of carboxyhemoglobinemia than in the case of an equivalent degree of methemoglobinemia. $^{2}$ In other words, at equivalent levels of

2 This may be illustrated by a consideration of Roughton's and Darling's oxygen dissociation curves in the presence of carboxyhemoglobinemia (14) and by the findings that about twice as much methemoglobinemia as carboxyhemoglobinemia is necessary to produce the same shift in the oxygen dissociation curve of the residual hemoglobin $(12,13)$. From Figure 1 of Roughton and Darling (14), the oxygen delivery in absence of any carboxyhemoglobinemia or methemoglobinemia between an arterial tension of $100 \mathrm{~mm}$. and a venous tension of $40 \mathrm{~mm}$. will be (96 per cent -74 per cent) $\times 20$ vols. per $100 \mathrm{ml}$., or 4.4 vols. per $100 \mathrm{ml}$. The same oxygen delivery in the presence of 40 per cent carboxyhemoglobin, would be ( 96 per cent -59.3 per cent) $\times 12$ vols. per 100 $\mathrm{ml}$. The venous and tissue oxygen tension at a venous saturation of 59.3 per cent would be $19 \mathrm{~mm}$. Since a 40 per cent methemoglobinemia may be considered to produce approximately the same shift as a 20 per cent methemoglobinemia and carboxyhemoglobinemia, tissues should be more sensitive to the anoxia of the latter. This may explain why dark adaptation may be more readily impaired in carboxyhemoglobinemia (8) than in methemoglobinemia. However, there are not enough data to permit a quantitative evaluation of the relative impairments in these 2 types of anoxia.

Of considerable interest is the finding that the threshold was affected by exercise. In nonmethemoglobinemic individuals, the threshold was not altered within 1 to 2 minutes after conclusion of the exercise, but was significantly higher 5 to 10 minutes after the end of exercise. In contrast, methemoglobinemic individuals showed a decrease in the threshold immediately after the end of exercise. About 5 to 10 minutes later, the threshold rose not only enough to negate this decrease, but also above the normal level, to an extent equal to that found in the non-methemoglobinemic individuals.

The changes in acid base equilibrium following short bouts of severe exercise were studied in considerable detail by Barr and Himwich (16). The amounts of work done ranged from 3500 to $4000 \mathrm{kgm}$. meters (equivalent to 25,000 to 30,000 foot pounds) in $3 \frac{1}{2}$ minutes, and therefore corresponded to the work loads in the present experiments. The $\mathrm{CO}_{2}$ capacity of the arterial blood was diminished during the second minute of exercise, and became progressively lower during the exertion and for several minutes ( 3 or more) after the exercise had ended. The return to normal $\mathrm{CO}_{2}$ capacity was gradual. The decreases in $\mathrm{pH}$ paralleled, in general, these decreases in $\mathrm{CO}_{2}$ capacity.

According to Wald, et al (3), acidosis causes a rise in the rod threshold, whereas alkalosis causes a decrease. The rise in rod threshold, both in methemoglobinemic and non-methemoglobinemic individuals, 5 to 10 minutes after exercise, may therefore be explained in terms of the acidosis of the post-exercise period. The decrease in the methemoglobinemic individuals immediately fol-

carboxyhemoglobinemia (13 to 15 ), an unloading of 4.4 vols. oxygen per $100 \mathrm{ml}$. would be accomplished by going from a 96 per cent saturation at $100 \mathrm{~mm}$. arterial tension to 59.3 per cent at $24 \mathrm{~mm}$. venous tension. Thus at equivalent degrees of carboxyhemoglobinemia and methemoglobinemia, the venous and tissue oxygen tensions are lower in carboxyhemoglobinemia. 
lowing exercise, and the absence of such a decrease in non-methemoglobinenic individuals, - do not agree with such an explanation. However, the arterial oxygen content (17) and the cardiac rate are increased immediately following a severe short bout of exercise, and the latter falls rapidly within 2 minutes after the end of exercise (18). Although it is possible that these factors influence the visual threshold and do so differently in the presence and absence of methemoglobin, data in the literature are inadequate to evaluate this influence.

\section{SUMMARY}

1. Concentrations of methemoglobin up to 30 per cent were induced without showing any definitely significant effect upon the rod threshold in dark adaptation either at sea level or at simulated high altitudes of 12,000 feet and 18,000 feet.

2. Short bouts of severe exercise lower the rod threshold immediately after exercise in methemoglobinemic individuals, but not in normal individuals. However, 5 to 10 minutes after exercise, the threshold rises above the normal threshold to the same extent in both methemoglobinemic and non-methemoglobinemic individuals.

3. The above findings are discussed with reference to oxygen unloading in tissues, and to the effect of exercise on the acid-base balance.

We are indebted to Dr. Selig Hecht for his help in planning the work reported here, to Dr. Bernard Jandorf and Miss Priscilla Day for their aid in conducting the experiments, and to Dr. Margaret Merrell for reviewing the statistical treatment. We also wish to thank the subjects, whose cooperativeness greatly facilitated our work.

\section{BIBLIOGRAPHY}

1. Jandorf, B. J., and Bodansky, O., Therapeutic and prophylactic effect of methemoglobinemia in inhalation poisoning by hydrogen cyanide and cyanogen chloride. J. Ind. Hygiene and Toxicology. 1946, 28, 125.

2. McFarland, R. A., and Evans, J. N., Alterations in dark adaptation under reduced oxygen tensions. Am. J. Physiol., 1939, 127, 37.

3. Wald, G., Harper, P. V., Jr., Goodman, H. C., and Krieger, H. P., Respiratory effects upon visual threshold. J. Gen. Physiol., 1942, 25, 891.
4. Hecht, S., Hendley, C. D., Frank, S., and Haig, C., Anoxia and brightness discrimination. Jour. Gen. Physiol., 1946, 29, 335.

5. Vandenbelt, J. M., Pfeiffer, C., Kaiser, M., and Sibert, M., Methemoglobinemia after administration of p-amino-acetophenone and p-aminopropiophenone. J. Pharmacol. and Exper. Therap., 1944, 80, 31.

6. Evelyn, K. A., and Malloy, H. T., Microdetermination of oxyhemoglobin, methemoglobin, and sulfhemoglobin in a single sample of blood. J. Biol. Chem., 1938, 126, 655.

7. Hecht, S., and Shlaer, S., An adaptometer for measuring human dark adaptation. J. Optic. Soc. America, 1938, 28, 269.

8. McFarland, R. A., Roughton, F. J. W., Halperin, M. H., and Niven, J. I., The effects of carbon monoxide and altitude on visual thresholds. J. Aviation Med., 1944, 15, 381.

9. Mandelbaum, J., Dark adaptation; some physiologic and clinical considerations. Arch. Ophth., 1941, 26, 203.

10. Asmussen, E., and Chiodi, H., The effect of hypoxemia on ventilation and circulation in man. Am. J. Physiol., 1941, 132, 426.

11. Chiodi, H., Dill, D. B., Consolazio, F., and Horvath, S. M., Respiratory and circulatory responses to acute carbon monoxide poisoning. Am. J. Physiol., 1941, 134, 683.

12. Darling, R. C., and Roughton, F. J. W., The effect of methemoglobin on the equilibrium between oxygen and hemoglobin. Am. J. Physiol., 1942, 137, 56.

13. Lester, D., and Greenberg, L. A., Comparative anoxemic effects from carbon monoxide hemoglobin and methemoglobin. J. Pharmacol. and Exper. Therap., 1944, 81, 182.

14. Roughton, F. J. W., and Darling, R. C., The effect of carbon monoxide on the oxyhemoglobin dissociation curve. Am. J. Physiol., 1944, 141, 17.

15. Albaum, H. G., and Bodansky, O., Unpublished observations.

16. Barr, D. P., Himwich, H. E., and Green, R. P., Studies in the physiology of muscular exercise. I. Changes in acid-base equilibrium following short periods of vigorous muscular exercise. J. Biol. Chem., 1923, 55, 495. Barr, D. P., and Himwich, H. E., II. Comparison of arterial and venous blood following vigorous exercise. J. Biol. Chem., 1923, 55, 525; III. Development and duration of changes in acid-base equilibrium. J. Biol. Chem., 1923, 55, 539.

17. Himwich, H. E., and Barr, D. P., Studies in the physiology of muscular exercise. V. Oxygen relationships in the arterial blood. J. Biol. Chem., 1923, 57, 363.

18. Johnson, R. E., Brouha, L., and Darling, R. C., Test of physical fitness for strenuous exertion. Rev. Canad. de Biol., 1942, 1, 491. 